\title{
Ulcerative Colitis - Prevention and Treatment with a Plant-Based Diet
}

\author{
Stewart D Rose and Amanda J Strombom* \\ Plant-Based Diets in Medicine, USA
}

Submission: May 21, 2020; Published: June 05, 2020

*Corresponding author: Amanda Strombom, Plant-Based Diets in Medicine, 12819 SE 38th St, \#427, Bellevue, WA 98006, USA

\begin{abstract}
Treating ulcerative colitis (UC) can be frustrating for doctor and patient alike. Therefore, practicing prevention with this disease is particularly desirable. Significant changes in dietary intake during the past decades have been associated with the increase in incidence of UC. A meta-analysis of seven epidemiological studies found meat intake to raise the risk of ulcerative colitis by $47 \%$. Consumption of fruits and vegetables have been found to significantly decrease the risk.

A plant-based diet can significantly reduce the risk or relapse in ulcerative colitis patients, almost as effectively as the leading drug, Mesalamine. Changes in the gut microbiome can be a potential prognostic feature. Improved biodiversity when consuming prebiotic plant foods, resulted in a significant increase in fecal butyrate levels. Fish oil and essential fatty acid supplements have not been found to be effective in the treatment and or maintenance of remission in ulcerative colitis.

Treating the ulcerative colitis patient with a plant-based diet has no contraindications or adverse reactions, is affordable and can prevent and treat common comorbidities such as type 2 diabetes and coronary artery disease. Vitamin D deficiency is common in people with ulcerative colitis and may be a contributing factor in the development of the disease and should be part of every workup.

Keywords: Butyrate; Inflammatory bowel disease; Meat intake; Microbiome; Plant-based diet; Prebiotics; Ulcerative colitis; Vegan; Vegetarian

Abbreviations: UC: Ulcerative Colitis; IBD: Inflammatory Bowel Disease; MCHC: Mean Corpuscular Hemoglobin Concentration; MCV: Mean Corpuscular Volume; IL: Interleukin; TNF- $\alpha$ : Tumor Necrosis Factor $\alpha$
\end{abstract}

\section{Introduction}

Samuel Wilks first described ulcerative colitis (UC) in 1859 [1]. Ulcerative colitis is a type of inflammatory bowel disease (IBD). It is characterized by continuous and diffuse inflammation that is limited to the colonic mucosa and extends proximally from the rectum. The disease develops most often in the second or third decade of life. The classic symptoms are bloody diarrhea, abdominal pain, and tenesmus [2]. Because the natural history of the disease is periods of remission and flares, medications are used in most cases to induce and maintain a longterm corticosteroid-free remission. Despite available medical treatments, approximately $15 \%$ of patients will require surgery for their disease $[3,4]$.

\section{Epidemiology}

Genetic factors are attributed to the risk of developing the disease, accompanied by epithelial barrier defects and environmental factors. Currently, a number of genetic and environmental factors that increase the risk of developing UC have been identified [5]. A westernized lifestyle and diet including cessation of tobacco use, consumption of animal products, stress, medication use and high socioeconomic status are all associated with the development of IBD [6]. Among many such factors, tobacco smoking and appendectomy are linked to milder disease, fewer hospitalizations, and decreased incidence of UC, but the reverse is true for Crohn's disease $[7,8]$.

Significant changes in dietary intake during the past decades have been associated with the increase in incidence of UC. The relationship between diet and UC development has been indicated in several epidemiological studies [9].

One study found a significant association between meat intake, red meat in particular, and UC risk. This meta-analysis of seven epidemiological studies found meat intake to raise the risk of ulcerative colitis by $47 \%$ [10]. Another study found that a high fat intake was associated with an increased risk for UC; this was particularly marked for animal fat which quadrupled the risk of ulcerative colitis [11]. A meta-analysis of fruit and vegetable consumption found that fruits and vegetables are associated with a significantly decreased risk of ulcerative colitis [12]. 


\section{Interventional studies}

A year-long prospective cohort study was performed with UC patients in remission who were followed for a year to determine the effect of habitual diet on relapse. High sulfur or sulfate intake increased the risk of relapse 2.7 times [13].

In a study of patients with mild UC or UC in remission who did not need immediate treatment, a residential program including a plant-based diet and dietary guidance was provided during a two-week period. The majority (77\%) of patients experienced improvements in symptoms and laboratory data during treatment. These same patients were then followed for 5 years and at 1, 2, 3, 4 , and 5 years, the relapse rates were $2 \%, 4 \%, 7 \%, 19 \%$, and $19 \%$, respectively [14]. These relapse rates are far better than those previously reported. For instance, a study of patients treated with aminosalicylates showed a relapse rate of $16 \%$ after only one year [15]. Other studies, without treatment with a plant-based diet, also showed higher rates of relapse [16-22].

A study characterizing the gut microbiome in a large cohort of pediatric patients with severe UC was the first to describe changes in the gut microbiome as a potential prognostic feature [23]. Richness, evenness, and biodiversity of the gut microbiome were remarkably reduced in children with UC compared with healthy controls. Children who did not respond to steroids harbored a microbiome that was even less rich than steroid responders.

Prebiotics are defined as non-digestible food ingredients that beneficially affect the host by selectively stimulating the growth or activity of bacterial species already present in the gut. Prebiotics, such as psyllium, are found in plant foods [24]. Because colonic fermentation of Plantago ovata seeds (psyllium) supports the bacteria that produce butyrate, it may have efficacy in treating ulcerative colitis. In a one-year study, consumption of 10mg BID Plantago ovata seeds was almost as effective as Mesalamine in maintaining remission. A significant increase in fecal butyrate levels was observed after Plantago ovata seed administration, thus reducing inflammation [25].

Fish oil and essential fatty acid supplements have not been found to be effective in the treatment and or maintenance of remission in ulcerative colitis [26]. Five placebo-controlled double-blind studies found no overall convincing clinical benefit of dietary fish oil supplementation for 4-12 months in the treatment of patients with active UC [27-31].

\section{Pathophysiology}

The multifactorial pathophysiology of UC includes genetic predisposition, epithelial barrier defects, dysregulated immune responses, microbial dysbiosis, and environmental factors [32,33].

Dietary factors can be related to UC pathogenesis or disease course through direct effects on the host, or through indirect effects through modulations of composition or function of gut microbiota. Diet plays a major role in shaping gut microbial composition [34,35]. Although the exact pathophysiological mechanisms in which diet plays a role in ulcerative colitis development remain unknown, several plausible explanations have been proposed, including its effects on the composition of gut microbiota, production of microbial metabolites, alterations in mucosal immunity, and mucosal barrier function [36].

A plant-based diet produces a greater quantity of butyrate and other short chain fatty acids, as well as supplying phytochemicals with anti-inflammatory properties. Plant-based dietary patterns may promote a more favorable gut microbial profile. Such diets are high in dietary fiber and fermentable substrate (i.e. non digestible or undigested carbohydrates), which are sources of metabolic fuel for gut microbial fermentation and, in turn, result in end products that may be used by the host (i.e. short chain fatty acids such as butyrate). These end products may have direct or indirect effects on modulating the health of their host [37].

The naturally occurring substances in plant foods having anti-inflammatory bowel actions include phytochemicals, antioxidants, dietary fibers, and lipids. The literature indicates that many of these compounds of plant foods exert their beneficial action by altering cytokine production. Specifically, phytochemicals such as polyphenols or flavonoids are the most abundant, naturally occurring anti-inflammatory substances. The effects of phytochemicals are associated with modulating the levels of tumor necrosis factor $\alpha$ (TNF- $\alpha$ ), interleukin (IL)1 , IL-6, inducible nitric oxide synthase, and myeloperoxide. The anti-ulcerative effects of dietary fiber are mainly mediated via peroxisome proliferator-activated receptor- $\gamma$, TNF- $\alpha$, nitric oxide, and IL-2, whereas the effects of lactic acid bacteria are reported to influence interferon- $\gamma$, IL-6, IL-12, TNF- $\alpha$, and nuclear factor- $\kappa$ light-chain enhancer of activated B cells. These results suggest that the anti-IBD effects exhibited by natural products are mainly caused by their ability to modulate cytokine production [38].

Studies, conducted using in vivo and in vitro models, provide evidence that polyphenolic compounds and natural polyphenolic plant extracts can modulate intestinal inflammation [39]. Polyphenols may thus be considered able to prevent or delay the progression of ulcerative colitis, especially because they reach higher concentrations in the gut than in other tissues [40].

It is thought that sulfide toxicity may be important in the pathogenesis of UC $[41,42]$. The initial evidence in this regard was a demonstration that experimental exposure of colonic tissue to sulfide causes inhibition of butyrate use, a defect similar to that observed in mucosal biopsies obtained from UC patients [43]. UC patients have significantly higher luminal concentrations of hydrogen sulfide than controls, and disease activity correlates with sulfide production rates [44]. Hydrogen sulfide induces hyperproliferation of colonic mucosa and this effect is antagonized by butyrate [45]. Treatment with 5-aminosalicylates and bismuth subsalicylates has been shown to reduce hydrogen sulfide production in the colonic lumen [46]. 
Exogenous sources, such as red meat, cheese, milk, fish and eggs, contribute to the colonic pool of sulfur $[26,47,48]$, whereas endogenous sources do not seem to make a significant contribution to the colonic pool of sulfur [44]. The major exogenous sources of sulfur are the sulfur amino acids found in high protein foods and inorganic sulfate (in brassica vegetables and as preservatives in processed foods, particularly commercial breads, beers, sausages, and dried fruit.) [49]. Sulfur amino acids and inorganic sulfate reach the colon where they are converted to sulfides by fermentation with colonic bacteria or by sulfatereducing bacteria $[50,51]$. Fecal hydrogen sulfide concentration increases when either the sulfur amino acid content (as meat) [52] or sulfate content (as additives) of the diet increase [53]. Generation of hydrogen sulfide by sulfate- reducing bacteria is modest compared with total fecal sulfide concentration $[47,54]$, suggesting that fermentation of sulfur amino acids may be the more important of the two mechanisms of generation of hydrogen sulfide.

Fecal sulfide levels increase after consumption of increasing amounts of meat [26,47], providing evidence that meat is an important substrate for sulfide generation by bacteria in the human large intestine. In a pilot study in which the intake of sulfur amino acids was limited, clinical improvement, in terms of stool frequency, was demonstrated in patients with UC [42].

The toxic effects of sulfur-reducing compounds, particularly hydrogen sulfide, at concentrations commonly found in the lumen of the human colon, appear to be mediated through impaired utilization of butyrate by colonocytes [55]. Hydrogen sulfide has been found to cause increased epithelial permeability, loss of barrier function [56], cellular proliferation [57], and histological changes in rat colons that are similar to those seen in humans with UC [45]. UC patients have significantly higher luminal concentrations of hydrogen sulfide than controls [58] and disease activity correlates with sulfide production rates [44].

Vegetarians tend to have higher fiber intakes [59], which could be metabolized by the colonic microbiota instead of amino acids, leading to a reduction in indoxyl sulfate and p-cresyl sulfate. This provides another mechanism to explain why vegetarian protein sources appear less detrimental than animal protein sources.

\section{Clinical considerations}

The goals of treatment are induction of remission followed by maintenance of remission in conjunction with steroid-free treatments in the long term management [60].

Current practice recommends lifelong medication for relapse prevention in IBD $[15,61,62]$. Current medications used in the treatment of ulcerative colitis include aminosalicylates, corticosteroids, immunomodulators and biologics. Diet, however, is critically important. Although medication is needed in the active phase of ulcerative colitis, diet is generally more important than medication to maintain remission in the quiescent phase
[15]. If a suitable diet is established as part of a changing lifestyle, medication ultimately may not be needed to maintain remission [15].

A suitable diet should be high in prebiotics. Fortunately, prebiotics occur naturally in many plant foods because they're components of nondigestible plant fibers. Some plant foods which are good sources of prebiotic fibers include chicory, garlic, leeks, onion, asparagus, and Jerusalem artichokes. They're also found in lesser amounts in bananas, whole wheat, yams, and sweet potatoes. Since the adequate intake for prebiotics is undefined, a diet that includes a diverse variety of high-fiber fruits and vegetables, especially foods high in prebiotics, has the most potential for obtaining sufficient amounts [63].

Vitamin D deficiency is common in people with ulcerative colitis with the prevalence being higher than the general population [64]. Vitamin D deficiency may also be a contributing factor in the development of ulcerative colitis [65]. Vitamin D as a therapeutic agent has shown promise in lowering relapse rates and bettering quality-of-life in ulcerative colitis patients [66].

Vitamin D is a pleiotropic hormone with a diverse range of effects ranging from immune modulation to cell differentiation and intercellular adhesion. Several in vivo and in vitro studies have examined the role of vitamin D in immune-mediated diseases such as ulcerative colitis [67-69]. The consequences of vitamin D deficiency on the gastrointestinal tract include, but are not limited to, decreased colonic bacterial clearance [70] reduced expression of tight junctions in the intestinal epithelium [71] and elevated Th1-driven inflammation at the gut level [72].

There is growing evidence that vitamin D status may affect disease activity. As such, consideration should be given to screening and management of vitamin D deficiency in this patient group $[73,74]$. Testing for Vitamin D deficiency should be part of every ulcerative colitis workup.

Other lab work should include B12 and, for potentially anemic patients, hemoglobin. Both the mean corpuscular volume (MCV) and the mean corpuscular hemoglobin concentration (MCHC) will also have values below the normal range for the laboratory performing the test. A colonoscopy can be performed as indicated.

The plant-based diet compares favorably with standard treatments. Treatment with a plant-based may take a little longer to become evident. Lab work should take this into account. It is also important to titrate the doses of medications as the treatment effects of a plant-based diet become evident. This is also the case if patients are being treated with antidiabetic, antihypertensive and anti-hypercholesterolemics concurrently.

\section{Discussion}

Ulcerative colitis is a lifelong illness that has a profound emotional and social impact on the affected patients. Treating ulcerative colitis can be frustrating for doctor and patient 
alike. The symptoms usually cause discomfort and many of the medications used to treat the disease have significant side effects. In addition, some of the medications are quite expensive resulting in a financial burden for the patient. Therefore, practicing prevention of this disease is particularly desirable.

If ulcerative colitis is accepted to be a lifestyle disease mainly caused, or exacerbated by a westernized diet, then current practice should move toward encouraging the patient to change their diet. A plant-based diet is naturally much higher in fiber than the average American diet, thus promoting the bacterial species in the gut that produce butyrate, resulting in lower inflammation.

A plant-based diet can significantly reduce the risk or relapse in ulcerative colitis patients, almost as effectively as the leading drug, Mesalamine. It can be used as a monotherapy or as an adjunct along with medications that are usually prescribed for ulcerative colitis patients.

Treating the ulcerative colitis patient with a plant-based diet has several advantages. It has no contraindications or adverse reactions, is affordable and can prevent and treat common comorbidities such as type 2 diabetes and coronary artery disease. It also reduces the risk of colon cancer, which is raised for long standing cases of ulcerative colitis patients.

Plant-based diets are no longer very unusual as they have become more popular in the general population in recent years. Given all of the benefits, the plant-based diet deserves a place among the physician's treatment options for ulcerative colitis.

\section{References}

1. Wilks S (1859) Morbid appearances in the intestine of Miss Bankes. Treating ulcerative colitis. Med Times Gazette 2.

2. Danese S, Fiocchi C (2011) Ulcerative colitis. N Engl J Med 365(18): $1713-1725$

3. Truelove S, Witts L (1955) Cortisone in ulcerative colitis; final report on a therapeutic trial. Br Med J 2(4947): 1041-1048.

4. Dignass A, Lindsay JO, Sturm A, Windsor A, Colombel JF, et al. (2012) Second European evidence-based consensus on the diagnosis and management of ulcerative colitis Part 2: Current management. J Crohns Colitis 6(10): 991-1030.

5. Ng S, Bernstein C, Vatn M, Lakatos P, Loftus E, et al. (2013) Geographical variability and environmental risk factors in inflammatory bowel disease. Gut 62(4): 630-649.

6. Danese S, Sans M, Fiocchi C (2004) Inflammatory bowel disease: the role of environmental factors. Autoimmun Rev 3(5): 394-400.

7. Birrenbach T, Böcker U (2004) Inflammatory bowel disease and smoking: a review of epidemiology, pathophysiology, and therapeutic implications. Inflamm Bowel Dis 10(6): 848-859.

8. Rutgeerts P, D’Haens G, Hiele M, Geboes K, Vantrappen G (1994) Appendectomy protects against ulcerative colitis. Gastroenterology106(5): 1251-1253.

9. Hou J, Abraham B, El-Serag H (2011) Dietary intake and risk of developing inflammatory bowel disease: a systematic review of the literature. Am J Gastroenterol 106(4): 563-573.
10. Ge J, Han TJ, Liu J, Lo JS, Zhang XH, et al. (2015) Meat intake and risk of inflammatory bowel disease: A meta-analysis. Turk J Gastroenterol 26(6): 492-497.

11. Reif S, Klein I, Lubin F, Farbstein M, Hallak A, et al. (1997) Pre-illness dietary factors in inflammatory bowel disease. Gut 40(6): 754-760.

12. Li F, Liu X, Wang W, Zhang D (2015) Consumption of vegetables and fruit and the risk of inflammatory bowel disease: a meta-analysis. Eur J Gastroenterol Hepatol 27(6): 623-630.

13. Jowett SL, Seal CJ, Pearce MS, Phillips E, Gregory W, et al. (2004) Influence of dietary factors on the clinical course of ulcerative colitis: a prospective cohort study. Gut 53(10): 1479-1484.

14. Chiba M, Nakane K, Tsuj T, Tsuda S, Ishii H, et al. (2018) Relapse prevention in ulcerative colitis by plant-based diet through educational hospitalization: A single-group trial. Perm J 22: 17-167.

15. Kawakami A, Tanaka M, Nishigaki M, Naganuma M, Iwao Y, et al. (2013) Relationship between non-adherence to aminosalicylate medication and the risk of clinical relapse among Japanese patients with ulcerative colitis in clinical remission: A prospective cohort study. J Gastroenterol 48(9): 1006-1015.

16. Moum B, Ekbom A, Vatn M, Aadland E, Sauar J, et al. (1997) Clinical course during the 1 st year after diagnosis in ulcerative colitis and Crohn's disease. Results of a large, prospective population-based study in southeastern Norway, 1990-93. Scand J Gastroenterol 32(10): 10051012.

17. Henriksen M, Jahnsen J, Lygren I, Sauar J, Kjellevold Ø. et al. (2006) Ulcerative colitis and clinical course: Result of a 5-year populationbased follow-up study (the IBSEN study). Inflamm Bowel Dis 12(7): 543-550.

18. Höie O, Wolters F, Riis L, Aamodt G, Solberg C, et al. (2007) Ulcerative colitis: patient characteristics may predict 10 -yr disease recurrence in a European-wide population-based cohort. Am J Gastroenterol 102(8): 1692-1701.

19. Solberg I, Lygren I, Jahnsen J,Aadland E, Høie O, et al. (2009) Clinical course during the first 10 years of ulcerative colitis: Results from a population-based inception cohort (IBSEN Study). Scand J Gastroenterol 44(4): 431-440.

20. Bebb JR, Scott BB (2004) How effective are the usual treatments for ulcerative colitis? Aliment Pharmacol Ther 20(2): 143-149.

21. Magro F, Rodrigues A, Vieira AI, Portela F, Cremers I, et al. (2012) Review of the disease course among adult ulcerative colitis populationbased longitudinal cohorts. Inflamm Bowel Dis 18(3): 573-583.

22. Kitano A, Okawa K, Nakamura S, Komeda Y, Ochiai K (2011) The longterm assessment of the patients with ulcerative colitis (> 10 years follow-up, mean followup 21.7 years). Journal of New Remedies \& Clinics 60(7): 1347-1355.

23. Michail S, Durbin M, Turner D, Griffiths A, Mack D, et al. (2012) Alterations in the gut microbiome of children with severe ulcerative colitis. Inflamm Bowel Dis 18(10): 1799-1808.

24. Van Loo J, Cummings J, Delzenne N, Englyst H, Franck A, et al. (1999) Functional food properties of non-digestible oligosaccharides: a consensus report from the ENDO project (DGXII AIRII-CT94-1095). Br J Nutr 81(2): 121-132.

25. Fernández-Bañares F, Hinojosa J, Sánchez-Lombraña L, Navarro E, Martínez-Salmerón J, et al. (1999) Randomized clinical trial of Plantago ovata seeds (dietary fiber) as compared with mesalamine in maintaining remission in ulcerative colitis. Spanish Group for the Study of Crohn's Disease and Ulcerative Colitis (GETECCU). Am J Gastroenterol 94(2): 427-433. 
26. Tilg H, Kaser A (2004) A Diet and relapsing ulcerative colitis: take off the meat? Gut 53(10): 1399-1401.

27. Lorenz R, Weber PC, Szimnau P, Heldwein W, Strasser T, et al. (1989) Supplementation with n-3 fatty acids from fish oil in chronic inflammatory bowel disease-a randomized, placebo-controlled, double-blind cross-over trial. J Intern Med Suppl 225(S731): 225-232.

28. Stenson WF, Cort D, Rodgers J, Burakoff R, DeSchryver-Kecskemeti K, et al. (1992) Dietary supplementation with fish oil in ulcerative colitis. Ann Intern Med 116(8): 609-614.

29. Hawthorne AB, Daneshmend TK, Hawkey CJ, Nelluzzi A, Everitt S, et al. (1992) Treatment of ulcerative colitis with fish oil supplementation: a prospective 12 month randomised controlled trial. Gut 33(7): 922928.

30. Aslan A, Triadafilopoulos G (1992) Fish oil fatty acid supplementation in active ulcerative colitis: a double-blind, placebo-controlled, crossover study. Am J Gastroenterol 87(4): 432-437.

31. Greenfield S, Green A, Teare J, Jenkins A, Punchard N, et al. (1993) A randomized controlled study of evening primrose oil and fish oil in ulcerative colitis. Aliment Pharmacol Ther 7(2): 159-166.

32. Ungaro R, Mehandru S, Allen P, Peyrin-Biroulet L, Colombel J (2017) Ulcerative colitis. Lancet 389(10080): 1756-1770.

33. Ramos G, Papadakis K (2019) Mechanisms of Disease: Inflammatory Bowel Diseases. Mayo Clin Proc 94(1): 155-165.

34. Brown K, DeCoffe D, Molcan E, Gibson DL (2012) Diet-induced dysbiosis of the intestinal microbiota and the effects on immunity and disease. Nutrients 4(8): 1095-1119.

35. Keshteli A, Madsen K, Dieleman L (2019) Diet in the pathogenesis and management of ulcerative colitis; A review of randomized controlled dietary interventions. Nutrients 11(7): E1498.

36. Khalili H, Chan S, Lochhead P, Ananthakrishnan A, Hart A, et al. (2018) The role of diet in the aetiopathogenesis of inflammatory bowel disease. Nat Rev Gastroenterol Hepatol 15(9): 525-535.

37. Wong J (2014) Gut microbiota and cardiometabolic outcomes: influence of dietary patterns and their associated components. Am Clin Nutr 100(Suppl 1): 369S-77S.

38. Hur S, Kang S, Jung H, Kim S, Jeon H, et al. (2012) Review of natural products actions on cytokines in inflammatory bowel disease. Nutr Res 32(11): 801-816.

39. Romier B, Schneider Y, Larondelle Y, During A (2009) Dietary polyphenols can modulate the intestinal inflammatory response. Nutr Rev 67(7): 363-378.

40. Biasi F, Astegiano M, Maina M, Leonarduzzi G, Poli G (2011) Polyphenol supplementation as a complementary medicinal approach to treating inflammatory bowel disease. Curr Med Chem 18(31): 4851-4865.

41. Roediger W, Moore J, Babidge W (1997) Colonic sulfide in the pathogenesis and treatment of ulcerative colitis. Dig Dis Sci 42(8): 1571-1579.

42. Roediger W (1998) Decreased sulphur aminoacid intake in ulcerative colitis. Lancet 351(9115): 1555.

43. Chapman M, Grahn M, Boyle M, Hutton M, Rogers J, et al. (1994) Butyrate oxidation is impaired in the colonic mucosa of sufferers of quiescent ulcerative colitis. Gut 35(1): 73-76.

44. Pitcher M, Beatty E, Cummings J (2000) The contribution of sulphate reducing bacteria and 5 -aminosalicylic acid to faecal sulphide in patients with ulcerative colitis. Gut 46(1): 64-72
45. Christl S, Eisner H, Dusel G, Kasper H, Scheppach W (1996) Antagonistic effects of sulphide and butyrate on proliferation of colonic mucosa: a potential role for these agents in the pathogenesis of ulcerative colitis. Dig Dis Sci 41(12): 2477-2481

46. Suarez F, Furne J, Springfield J, Levitt M (1998) Bismuth subsalicylate markedly decreases hydrogen sulfide release in the human colon. Gastroenterology 114(5): 923-929.

47. Magee E, Richardson C, Hughes R, Cummings J (2000) Contribution of dietary protein to sulphide production in the large intestine: an in vitro and a controlled feeding study in humans. Am J Clin Nutr 72(6): 1488-1494.

48. Richardson C, Magee E, Cummings J (2000) A new method for the determination of sulphide in gastrointestinal contents and whole blood by microdistillation and ion chromatography. Clin Chim Acta 293(1-2): 115-125.

49. Florin T, Gibson G, Neale G, Cummings J (1990) A role for sulfate reducing bacteria in ulcerative colitis? Gastroenterology 98: A170.

50. Florin T, Neale G, Gibson G, Christl S, Cummings J (1991) Metabolism of dietary sulphate: absorption and excretion in humans. Gut 32(7): 766-773.

51. Florin T, Neale G, Goretski S, Cummings J (1993) The sulfate content of foods and beverages. J Food Composition Anal 6: 140-151.

52. Geypens B, Claus D, Evenepoel P, Hiele M, Maes B, et al. (1997) Influence of dietary protein supplements on the formation of bacterial metabolites in the colon. Gut 41(1): 70-76.

53. Gibson G, Cummings J, Macfarlane G (1988) Use of a three-stage continuous culture system to study the effect of mucin on dissimilatory sulfate reduction and methanogenesis by mixed populations of human gut bacteria. Appl Environ Microbiol 54(11): 2750-2755.

54. Magee E, Richardson C, Cummings J (2001) Dietary precursors of sulphide in the human large intestine. Proc Nutr Soc 60: 16A

55. Ohkusa $\mathrm{T}$ (1985) Production of experimental ulcerative colitis in hamsters by dextran sulfate sodium and changes in intestinal microflora. Jpn J Gastroenterol 82(5): 1327-1336.

56. Roediger W, Duncan A, Kapaniris O, Millard S (1993) Reducing sulfur compounds of the colon impair colonocyte nutrition: implications for ulcerative colitis. Gastroenterology 104(3): 802-809.

57. Ng W, Tonzetich J (1984) Effect of hydrogen sulfide and methyl mercaptan on the permeability of oral mucosa. J Dent Res 63(7): 994997.

58. Aslam M, Batten J, Florin T, Sidebotham R, Baron J, et al. (1992) Hydrogen sulphide induced damage to the colonic mucosal barrier in the rat. Gut 33: 569

59. Bammens B, Evenepoel P, Keuleers H, Verbeke K, Vanrenterghem Y (2006) Free serum concentrations of the protein-bound retention solute p-cresol predict mortality in hemodialysis patients. Kidney Int 69(6): 1081-1087.

60. Kornbluth A, Sachar D (2010) Ulcerative colitis practice guidelines in adults: American College of Gastroenterology, Practice Parameters Committee. Am J Gastroenterol 105(3): 501-523.

61. Kane SV (2007) Overcoming adherence issues in ulcerative colitis Gastroenterol Hepatol (N Y) 3(10): 795-799.

62. Jackson C, Clatworthy J, Robinson A, Horne R (2010) Factors associated non-adherence to oral medication for inflammatory bowel disease: A systematic review. Am J Gastroenterol 105(3): 525-539. 
63. Coleman Collins S (2014) Entering the world of prebiotics - are they a precursor to good gut health? Today's Dietitian 16(12): 12.

64. Fletcher J, Swift A (2017) Vitamin D screening in patients with inflammatory bowel disease. Gastrointest Nurs 15: 16-23.

65. Cantorna MT (2006) Vitamin D and its role in immunology: Multiple sclerosis, and inflammatory bowel disease. Prog Biophys Mol Biol 92(1): 60-64.

66. Del Pinto R, Pietropaoli D, Chandar A, Ferri C, Cominelli F (2015) Association between inflammatory bowel disease and vitamin D deficiency: a systematic review and meta-analysis. Inflamm Bowel Dis 21(11): 2708-2717.

67. Ardizzone S, Cassinotti A, Trabattoni D, Manzionna G, Rainone V, et al. (2009) Immunomodulatory effects of 1,25-dihydroxyvitamin D3 on TH1/TH2 cytokines in inflammatory bowel disease: an in vitro study. Int J Immunopathol Pharmacol 22(1): 63-71.

68. Di Rosa M, Malaguarnera G, De Gregorio C, Palumbo M, Nunnari G, et al. (2012) Immuno-modulatory effects of vitamin D3 in human monocyte and macrophages. Cell Immunol 280(1): 36-43.
69. Cantorna M, Munsick C, Bemiss C, Mahon B (2000) 1,25-Dihydroxycholecalciferol prevents and ameliorates symptoms of experimental murine inflammatory bowel disease. J Nutr 130(11): 2648-2652.

70. Lagishetty V, Misharin A, Liu N, Lisse T, Chun R, et al. (2010) Vitamin $\mathrm{D}$ deficiency in mice impairs colonic antibacterial activity and predisposes to colitis. Endocrinology 151(6): 2423-2432.

71. Kong J, Zhang Z, Musch M, Ning G, Sun J, et al. (2008) Novel role of the vitamin $\mathrm{D}$ receptor in maintaining the integrity of the intestinal mucosal barrier. Am J Physiol Gastrointest Liver Physiol 294(1): G208-G216.

72. Cantorna M, Zhu Y, Froicu M, Wittke A (2004) Vitamin D status, 1,25-dihydroxyvitamin D3, and the immune system. Am J Clin Nutr 80(6 Suppl): 1717S-1720S.

73. Bancil A, Poullis A (2015) The Role of Vitamin D in Inflammatory Bowel Disease. Healthcare (Basel) 3(2): 338-350.

74. Rose S, Strombom A (2019) Ensuring adequate vitamin D status for patients on a plant-based diet. Ortho \& Rheum Open Access J 15(3): 555913.

\section{Your next submission with JuniperPublishers will reach you the below assets}

- Quality Editorial service

- Swift Peer Review

- Reprints availability

- E-prints Service

- Manuscript Podcast for convenient understanding

- Global attainment for your research

- Manuscript accessibility in different formats

( Pdf, E-pub, Full Text, audio)

- Unceasing customer service

Track the below URL for one-step submission https://juniperpublishers.com/online-submission.php 